\title{
Aromatherapy in the intensive care unit: an
} overview

Anneliese Raab, Stationsschwester, Allgemeines Krankenhaus der Stadt Wien, Universitätskliniken Univ. Klinik für Chirurgie, Klin. Abt. für Allgemeinchirurgie, Intensivpflegestation 13 B1, Austria

Key Words: aromatherapy * complementary therapy * essential oils * intensive care *

E-mail: anneliese.raab@akh.wien.at

\section{ESPAÑOL}

Aromaterapia en la unidad de cuidado intensivo: una visión general

\section{Palabras clave}

Aromaterapia, cuidado intensivo, terapia complementaria

\section{Resumen}

La aromaterapia se brinda como un tratamiento adicional al tratamiento médico en varias unidades de cuidado intensivo.

Los aceites esenciales son fácilmente absorbidos por la piel en el término de veinte a sesenta minutos.

La literatura revela que el uso de aromaterapia puede ayudar a reducir la frecuencia cardiaca, disminuir el dolor y aumentar el bienestar en pacientes de cuidado intensivo.

Siguiendo los principios establecidos por la Asociación Norteamericana de Diagnósticos de Enfermería (NANDA), la aromaterapia podría utilizarse en pacientes con alta temperatura, con reducida integridad de la piel, inactividad, confusión y en el fin de la vida.

La aromaterapia se realiza utilizando una variedad de métodos de aplicación, incluyendo el baño, los vendajes, masajes, aplicación local y atomización.

\section{SUMMARY}

- Aromatherapy is provided as an additional treatment to medical treatment in many intensive care units.

- Essential oils are easily absorbed from the skin within twenty to sixty minutes.

- The literature reveals that use of aromatherapy can help to reduce heart rate, decrease pain and increase the wellbeing of intensive care patients.

- Following principles established by the North American Nursing Diagnosis Association (NANDA), aromatherapy may be used for patients with high temperature, reduced skin integrity, inactivity, confusion, and at end-of-life.

- Aromatherapy is performed using a variety of methods of application, including bathing, wrappings, massage, local application, and spray.

\section{INTRODUCTION}

Aromatherapy is the application of aromatic, or essential oils. Within the intensive care unit (ICU), their use is not considered to be medically therapeutic as such, but rather as a complementary therapy. The application of essential oils may be described as a supplementary nursing method, which was defined by Graf (1994) as follows:

- A human and ecologically beneficial form of nursing work, away from old, frozen concepts, which have become a routine, towards a responsible differentiated nursing method taking the patient's wishes and practicability of the situation into account, with the aim to preserve, stimulate or restore independence.

Essential oils are mainly vegetable oils which, depending on their origin, contain different fragrances. They are different from conventional oils (for example, sunflower oil) because they evaporate completely and do not leave a characteristically oily stain on paper; they are sometimes called dry oils.

The quality of essential oils plays an important role in aromatherapy. Oils used must be authentic and $100 \%$ pure. When an oil is extracted, manufacturers record information about the quality of the oil including detailed information about plant name, its origin, cultivation, parts of the plant that were used, extraction, batch or charge number, and relevant expiry dates. Differences in quality can result from plant growth in regions with too little rain or too much rain, or not enough sun (comparable to differences in taste between wine regions). This happens because the plant is extremely dependant on its climatic surrounding. Quality can also be affected by pesticide use or pollution of air and soil.

It is recommended that only pure essential oils are used therapeutically. If a mineral oil is added, it cannot be absorbed by the skin due to its large molecular structure. Mineral oils remain on the skin, preventing it from breathing, and block sebaceous glands, which reduce production and eventually cease working (Sachsenmaier, 2000).

When essential oils are used therapeutically, high-grade essences (fragrance molecules) first reach the olfactory organ, the olfactory mucous membrane and the olfactory cells, which are equipped lined by cilia, which contain receptor proteins. The fragrant 'message' of the oil is transformed into electrical nerve signals that move past nerve projections through the ethmoid bone plate before reaching the brain. The individual recognises this as 'smell' and there is an associated emotional response. After thirty years of research work at the University of Utah in USA, David Berliner revealed a "second smelling" of humans. He described the function of the vomeronasal organ - also called the Jakobson Organ - which is located at the base 
of the nasal cavity. Named after Ludwig Jacobson, the organ was first discovered in animals. It is primarily responsible for the detection of pheromones. Pheromones are substances for sexual enticement, defence, alarm or trace marking. In humans, they are produced in the skin and in the sweat glands, presumably from sexual hormones, and are effective in very small doses (Zimmermann, 2004). Essential oils contain not only the usual scents but also pheromone-like substances. When the vomeronasal organ is stimulated a signal is passed on to the hypothalamus, where moods are regulated.

Essential oils are applied to the skin using a number of methods, of which the most common are bathing, compresses, wrappings, massage, oral rinsing, local application and sprays. Essential oils consist of fat-soluble molecules; the cell-walls are made of unsaturated fatty acids. Oils can enter the upper most skin layer by diffusion and continue to the deeper layer of the skin through the sweat or sebaceous glands. They make their way into the bloodstream via the smallest blood capillaries. Diffusion also occurs because most ingredients of essential oils have a low molecular weight of about 225 Dalton. The $\mathrm{pH}$ and condition of the skin influences the speed and rate of absorption. The abdomen, back and legs are comparatively impermeable, whereas all mucous membranes are very permeable. Warm skin, with a good blood supply and a high degree of moisture stimulate the infiltration of the oil (Zimmermann, 2004).

Massage is a common form of essential oil application. Oils are applied in a diluted form of around $1 \%$ essential oil mixture. So they do not evaporate, they need to be dissolved in carrier oils, to be able to enter the body. Most oils enter the bloodstream after twenty to sixty minutes and can be detected in exhaled air.

\section{AROMATHERAPY IN INTENSIVE CARE NURSING}

Over the last two decades, there has been a number of reports of the use of aromatherapy in nursing, however there has been little empirical research to guide practice (Maddocks-Jennings \& Wilkinson, 2004). From the early 1990s onward, there has been several reports of their use in ICU and in one UK study approximately $50 \%$ of critical care units used some form of complementary therapy (Hayes and Cox, 1999). However, there have been few research studies in ICU. Woolfson and Hewitt (1992) performed massage on 100 ICU patients of whom $50 \%$ were receiving artificial ventilation. Group A received massage with lavender oil and group B received massage only. $90 \%$ of the patients in group A showed a reduced heart rate of $11-15$ beats per minute, whereas a similar reduction was seen in only $58 \%$ of group $B$.

In a UK experimental study of aromatherapy use in ICU, the results demonstrated that aromatherapy using $1 \%$ lavender oil was associated with a significant reduction of fear (Dunn et al., 1995). There may also be benefits for ICU nurses. In a small study by Pemberton and Turpin (2008) the topical application of essential oils was found to reduce work-related stress.

In summary, the evidence for therapeutic use of essential oils is weak, and although its greatest benefit is to enhance relaxation, there are concerns about potential risks (Maddocks-Jennings \& Wilkinson, 2004).

\section{Aromatherapy in the general surgical ICU: our experience}

ICU patients find themselves in an exceptional situation, which can be a depersonalising and dehumanising event, leading to decreased motivation, apathy and withdrawal. The patient's feeling of solitude may be intensified when visitors, due to fear of causing further pain, avoid physical contact. Our years of experience in ICU support this. In our ICU, our aim is to provide the best possible care for patients, taking into consideration all relevant factors. In this context, we have found the use of essential oils to be an effective complementary therapy.
We have been using aromatherapy in our ICU with great success since 1999 , and $87 \%$ of our staff have undertaken two to four-day education programs in its use. We use aromatherapy in the following areas:

- Body washing using essential oils, according to the patients needs

- $\quad$ Skin care

- Prophylactic application in cases of intertrigo (inflammation of skin folds)

- $\quad$ Assisting the patients to fall asleep

- Providing a comfortable environment with room scents

There are several important areas to be considered when applying essential oils:

- Ensure the patient's smell and taste preferences and any allergies are recorded in their medical/nursing notes

- Ensure that it is nurses only who apply the oils (as apposed to the patient or relative)

- Contraindications, for example, epilepsy

- Known of possible incompatibilities

- Appropriate consultation with physician colleague when used with homoeopathic treatment

- To avoid habituating effects in long-term patients, the first week of every month should provide a break from aromatherapy

- The basic oil mixtures are provided by the hospital pharmacy

- $\quad$ Oils are not applied more than three times daily

- Undiluted essential oils are never to be used on the skin

All of our documentation and evaluation of interventions using essential oils follows the principles established by NANDA for these types of treatments.

\section{Hyperthermia}

The nursing intervention is achieved using temperature-reducing calf wrappings (see Photo 1) or washing with lemon or fine lavender, using sea salt or cream as an emulsifying agent. When using temperaturereducing wrappings it is essential to note that success depends on time resources and professional execution. The duration of this intervention should be about 30-40 minutes including three to four changes of the wrappings. It is important to avoid a rapid decrease in body temperature and associated cardiovascular instability.

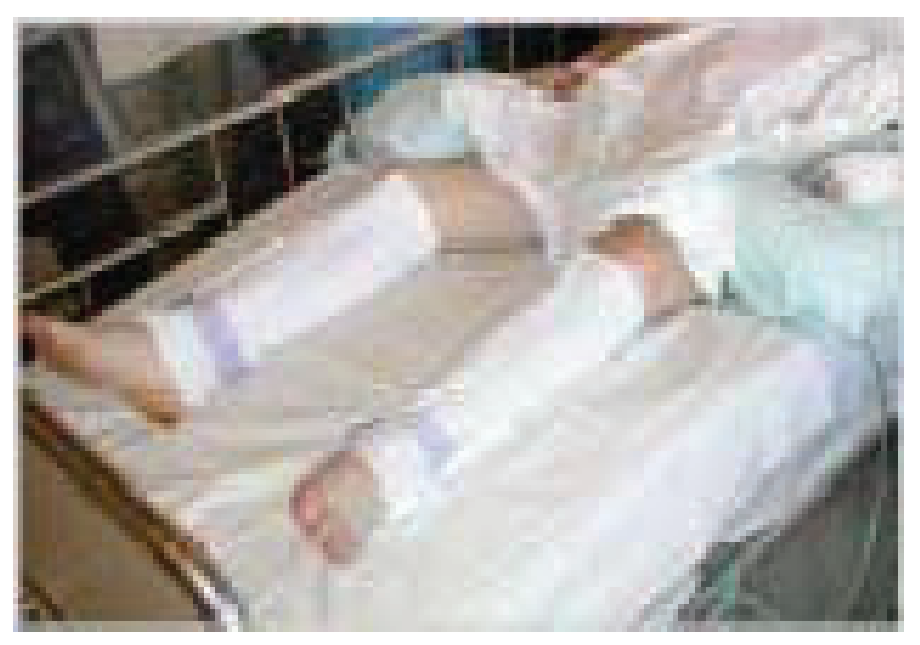

Photo. 1: Wrappings to reduce temperature 


\section{Skin integrity, high risk}

To reduce the risk of further inflammation and skin breakdown an intertrigo oil blend of base oil, lavender, and tea tree is applied to the endangered areas (see Photos 2a, 2b).

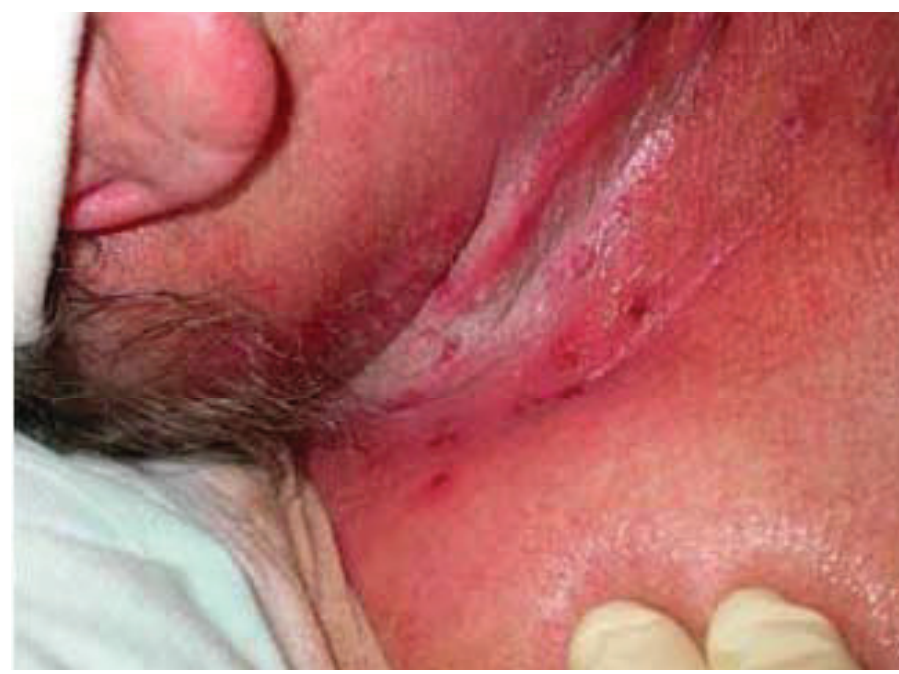

Photo 2a: Day 1

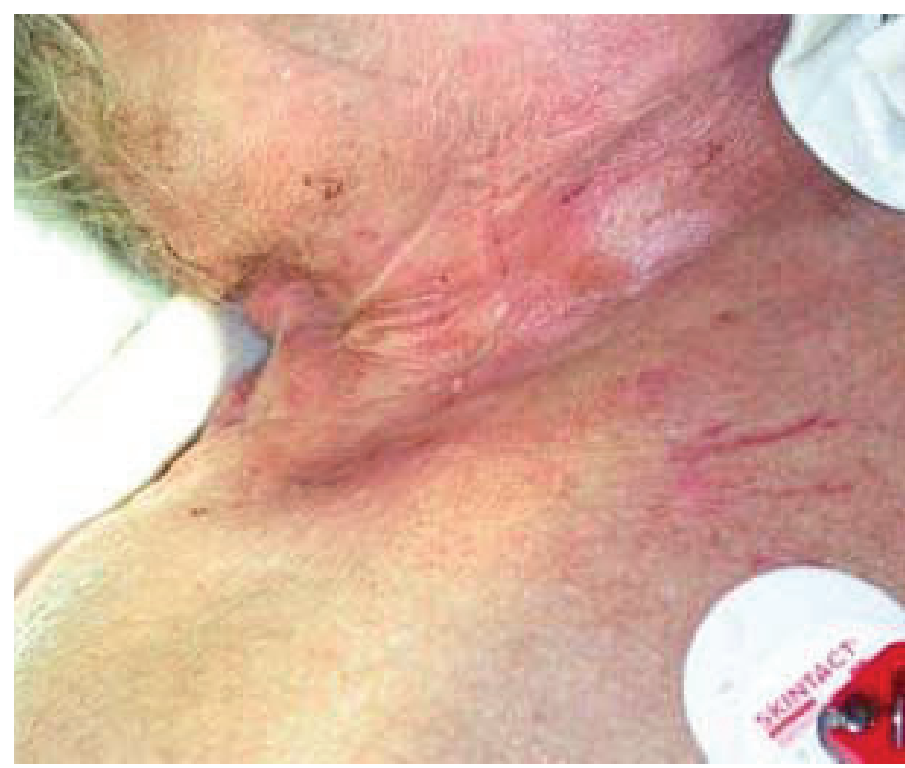

Photo 2b: Day 5

\section{Activity intolerance}

All skin care applications with essential oils have a double effect. The effect on the skin is accompanied by the limbic response. Different scents can be used to enhance emotions or enforce memory. These effects are limited in patients who are intubated and those who have a tracheostomy.

Hand massage (see Photos 3a, 3b) has a comforting and soothing effect. By drawing attention towards the hand, the patient is made more aware of it again. The quality of this physical contact is of course a crucial point concerning the stroking or rubbing with basic mixtures. For hand massage a blend of base oil, lavender, and sandalwood is applied to the skin.

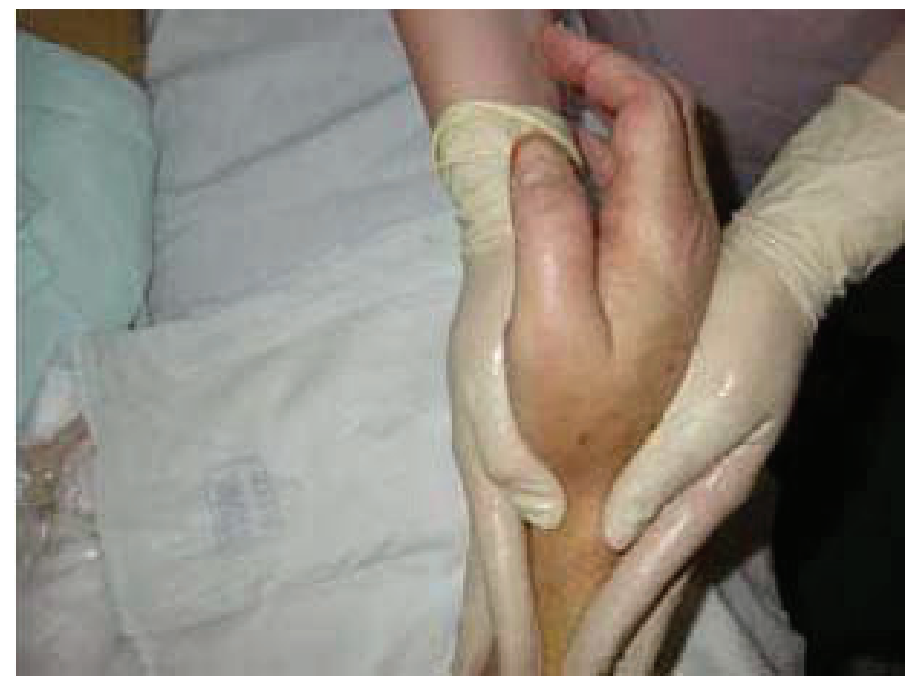

Photo 3a. Hand massage/stroking

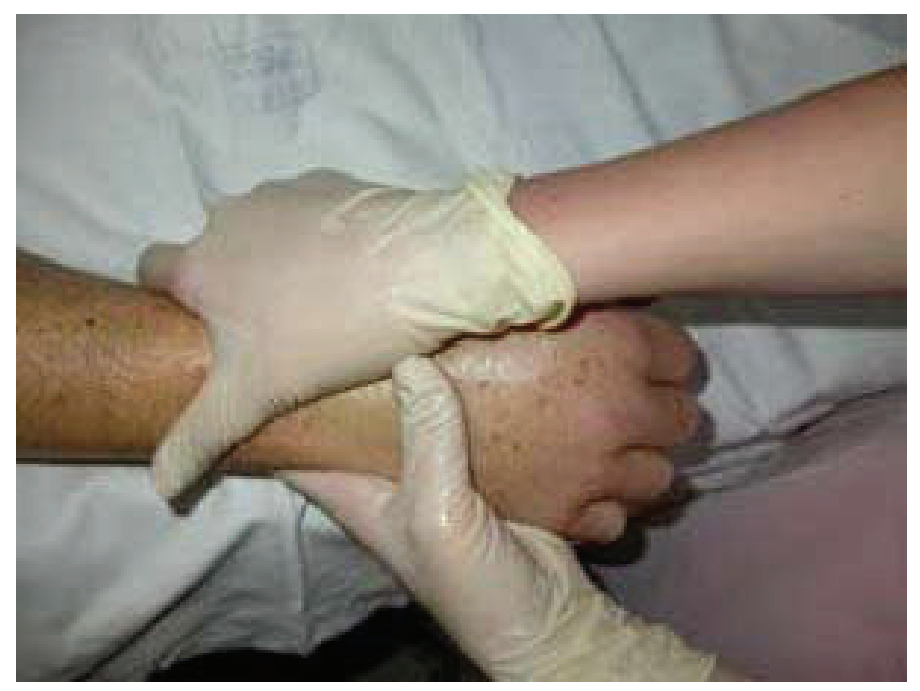

Photo 3b. Hand massage/rubbing

\section{Disturbed sensory perception}

The aim is to enhance comfort as well as to improve motivation and alertness, and to reduce weakness. This is achieved by treatment with use of a stimulating body oil blend of base oil, lavender, lemon, and cajuput. Diffusion of the oil mix is best achieved via the soles of the feet (without calluses), the palms of the hands, the skin of the head and forehead, the crook of the arm, the scrotum and all other areas of the body that have a rich capillary blood supply. Also effective is a stimulating body wash using an emulsifying agent with lavender, lemon, and cajuput. The rubbing or washing is performed against the direction of hair growth, which is more stimulating. Photos $4 \mathrm{a}$ and $4 \mathrm{~b}$ show the shoulder massage combining both, kinaesthetic and essential oils in order to relax joints.

\section{Acute confusion}

For patients with this diagnosis, the following the following additional nursing treatment can be applied:

- $\quad$ Soothing body oil using base oil with lavender and bergamot 
- $\quad$ Soothing washings of the complete body using an emulsifying agent with lavender and bergamot

When patients are experiencing withdrawal symptoms, the following are used:

- Balancing body wash using an emulsifying agent with lavender and sandalwood

- Body oil (base oil with lavender, cedar, and bergamot

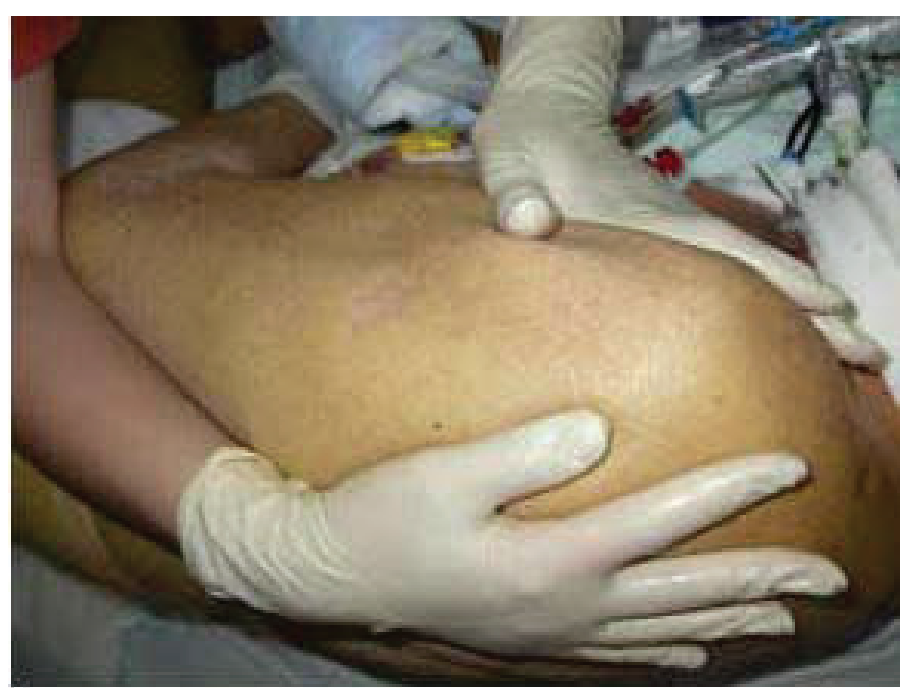

Photo 4a. Circular shoulder movement

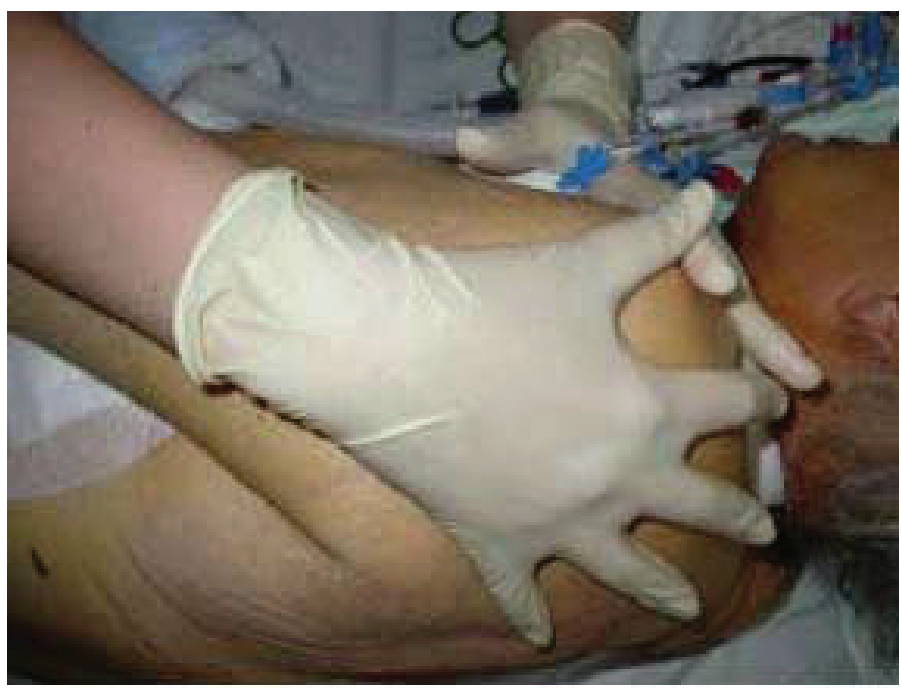

Photo 4b. Reduction of muscular tonus

\section{Airway clearance, ineffective}

A stimulating rub, comprising base oil with lavender and cajuput is applied to the chest and back. This helps to reduce the respiratory rate as well as assisting mobilisation of bronchial secretions. This is helpful when weaning patients from the ventilator. The effect of the oil is enhanced by a breath-stimulating massage technique performed in direction of hair growth.

\section{End-of-life care}

A patient should not be left alone, when he or she is dying, and soothing physical contact demonstrates presence, attentiveness, and respect. When providing end-of-life care, an oil blend of base oil with lavender, rose, grapefruit, and cedar is applied to enhance comfort. Our experience has shown that this measure is thankfully accepted by relatives. How (and whether) the oil blend is applied though should take the patient's and the relatives' preferences into consideration. Death is a challenging time for all, and it is important to ensure that the last hours of a patient's life are as comfortable as possible.

\section{SUMMARY}

Based upon our experiences, the use of aromatherapy has demonstrated a perceptible increase in patients' comfort and stress reduction. Also, the environment created by the use of essential oil makes patients, relatives, and nursing staff feel more comfortable. This fact has been confirmed by feedback from former patients as well as their relatives. Furthermore, there has been increased interest from staff regarding the use of alternative and complementary nursing methods to enhance patient care. For us, the use of essential oils provides a piece of humanity in an often hasty and technical day of nursing work. Whereas in the past there was scepticism from medical staff towards this kind of therapy, there is now a supportive attitude for the well-being of the patient.

\section{REFERENCES}

Buchbauer G (2004). Über biologische Wirkung von Duftstoffen und ätherische Öle. [On the biological properties of fragrance compounds and essential oils]. Wiener Medizinische Wochenschrift 154 (21-22), 539-547.

Christen L, Christen S, Waldmeier V, Osterlund S, Morgenthaler U, Scheidegger J, Oehninger R (2003). Pflege ohne und mit Anwendung von ätherischen Ölen: eine kontrollierte Studie mit Patienten und Patientinnen einer rheumatologischen Akutabteilung. [Nursing without and with essential oils: a controlled study of patients in an acute rheumatologic department.] Pflege 16 (5), 193-201.

Dunn C, Sleep J, Collet D (1995). Sensing an improvement: an experimental study to evaluate the use of aromatherapy, massage and periods of rest in an intensive care unit. Journal of Advanced Nursing 21 (1), 34-40.

Graf H (1994). Praxisrelevante alternative Pflegemethoden. [Practice-relevant alternative nursing methods.] Die Schwester/ Der Pfleger; 7.

Hayes JA, Cox CL (1999). The integration of complementary therapies in North and South Thames Regional Health Authoirities' critical care units. Complementary Therapies in Nursing and Midwifery 5 (4), 103-107.

Maddocks-Jennings W, Wilkinson JM. 2004 Aromatherapy practice in nursing: literature review. Journal of Advanced Nursing 48 (1), 93-103.

Pemberton E, Turpin PG (2008). The effect of essential oils on work-related stress in intensive care unit nurses. Holistic Nursing Practice 22 (2), 97-102.

Sachsenmaier B (2000). Professionelle Hautpflege. [Professional Skin Care.] Stuttgart: W. Kohlhammer.

Woolfson A, Hewitt D (1992). Intensive aromacare. International Journal of Aromatherapy 4 (2), 12-13.

Zimmermann E (2004). Aromatherapie für Pflege- und Heilberufe. [Aromatherapy for Nurses and Health Carers.] Stuttgart: Medizinverlag. 